\title{
Parenting Attitudes and General Health in Mothers of Children With Attention Deficit Hyperactivity Disorder
}

\author{
Ashraf Tashakori ${ }^{1, *}$; Soroor Neamatpour ${ }^{1}$; Azade Saki ${ }^{2}$

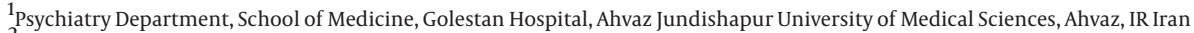 \\ ${ }^{2}$ School of Public Health, Ahvaz Jundishapur University of Medical Sciences, Ahvaz, IR Iran \\ ${ }^{*}$ Corresponding author: Ashraf Tashakori, Psychiatry Department, School of Medicine, Golestan Hospital, Ahvaz Jundishapur University of Medical Sciences, Ahvaz, IR Iran. Tel: +98- \\ 989163135002, E-mail: Tashakori_doctor @yahoo.com
}

Received: August 8, 2014; Revised: November 25, 2014; Accepted: December 14, 2014

\begin{abstract}
Background: Mothers of children with attention deficit hyperactivity disorder (ADHD) may have distinctive parenting attitudes and mental health problems.

Objectives: This study examined the parenting attitudes, general health, and some other related factors in mothers of children with ADHD.

Materials and Methods: Sixty mothers of children with ADHD who referred to psychiatric outpatient clinic of Ahvaz Golestan Hospital were selected by convenience sampling method. The parenting attitude, general health, and demographic data questionnaires were used. Results: Forty two (70\%) mothers were healthy and 18 (30\%) were unhealthy. The Pierson coefficient and the Fisher's exact test showed only a significant relationship in maternal age with the total score of general health questionnaire $(\mathrm{GHQ})(\mathrm{r}=-0.350, \mathrm{P}=0.05)$ and the score of anxiety subscale $(r=-0.429, P=0.05)$. The scores of different attitudes were $29.45 \pm 5.71$ for dominating, $29.13 \pm 6.08$ for ignoring, and $27.8 \pm$ 5.8 for possessive attitudes. Mothers with elementary school education level had fewer possessive attitude than higher educated mothers $(\mathrm{P}=$ 0.017). The ignoring attitude was significantly higher in staff members than others $(\mathrm{P}=0.043)$. Logistic regression model also showed that the GHQ score was significantly related to maternal age $(P=0.027)$ and number of children $(P=0.011)$.

Conclusions: Dominating, ignoring and possessive attitudes are frequent in mothers of children with ADHD. Parenting attitudes in mothers of children with ADHD may have relationships with job and education level. Mothers of children with ADHD, especially in younger ages and more offsprings may be predisposed to mental health problems, especially to anxiety.
\end{abstract}

Keywords:Parenting; Attitudes; Attention Deficit Hyperactivity Disorder; Health, Mothers

\section{Background}

According to the text revision of the fourth edition of Diagnostic and Statistical Manual of Mental Disorders (DSM-IV-TR), attention deficit hyperactivity disorder (ADHD) is a childhood onset and permanent pattern of developmentally inappropriate inattention and/or hyperactivity (1). ADHD is one of the most common childhood psychiatric disorders in outpatient setting with 2-19\% worldwide prevalence (2-6). Children with ADHD may cause high stress in their parents due to their behavioral problems. Parents of these children report low quality of life, deficits in current family functioning, low parenting satisfaction, high psychological health problems, and low social and family support (7-9). Mothers of children with ADHD, due to self ADHD diagnosis and treatment application, may have impairment in parenting (8-10). Parental problems and cognitive errors may affect their attitudes toward the child and these factors interfere with their responsibility and reaction to the child (11). They may describe their children as impulsive, nervous and aggressive (12), and they also get confused about the reason, diagnosis and treatment of their chil- dren (13). They may have inadequate discipline and different parenting styles $(7-10,14,15)$. Parenting style has been identified as a general pattern of parent's methods for childrearing and family functioning as well as their relationship. Four distinct parenting styles have been classified based on two underlying dimensions of warmth and control: authoritative, authoritarian, neglecting, and permissive (16). Parenting styles may be in light of parenting attitudes. Parenting attitudes are belief, emotion and readiness of parents for childrearing management (17). Parents with dominating attitude have authoritarian parenting styles. These parents give instruction to the child without explanation and they expect the child to follow the parent's standards. Furthermore, these parents often use limit setting. Parents with possessive attitude use permissive parenting styles. These parents frequently use overprotection to control the child and they provide everything for them, so that these children may become dependent and spoiled. Parents with ignoring attitude have neglectful parenting styles. These parents neither show intimacy to the children nor supervise

Copyright (C) 2015, Ahvaz Jundishapur University of Medical Sciences. This is an open-access article distributed under the terms of the Creative Commons Attribution-NonCommercial 4.0 International License (http://creativecommons.org/licenses/by-nc/4.0/) which permits copy and redistribute the material just in noncommercial usages, provided the original work is properly cited. 
them. In addition, they do not use reward and punishment in parenting management. There have been many studies about parenting styles, but there are limited studies about parenting attitudes. There is a circular causality pattern between the child's behaviors, parenting attitudes or styles, and parental psychic state. In other words, disturbance in each factor can start a pathological cycle in this system. Mothers are often the primary caregiver of children and they have closer relationship and more proximity to them; therefore, they are affected by children's behavioral problems, so that they will refer to psychiatric clinic.

\section{Objectives}

This study was carried out to examine parenting attitudes, general health, and some their related factors in mothers of children with ADHD.

\section{Materials and Methods}

This descriptive study was approved by the Research Board Committee of Ahvaz Jundishapur University of Medical Sciences, carried out in 2012. Sixty mothers of children with ADHD who referred to the psychiatric outpatient clinic of Ahvaz Golestan Hospital and expressed their consent were selected by convenience sampling method. ADHD was diagnosed by interviewing a child and adolescent psychiatrist based on DSM-IV-TR. General health questionnaire (GHQ) (the 28-item form), demographic data questionnaire, and parenting attitude questionnaire were used.

\subsection{General Health Questionnaire}

This is the best tool for diagnosis and self-report screening for psychiatric disorders, made by Goldberg and Hillier. It is used for investigation of a probable psychiatric disorder and distinction of healthy and unhealthy individuals; but, it cannot distinguish a specific category of psychiatric disorder. This questionnaire has been designed for all community members. It has four subscales: somatic symptoms, anxiety-insomnia, social withdrawal, and depression. Each subscale has seven questions and each question is rated from 0-3. Therefore, score for each subscale range between 0-21 and the total score for GHQ28 ranges between $0-84$. The mean sensitivity of GHQ-28 is $84 \%$ and its mean specificity is $82 \%(18)$. This questionnaire has been translated into Farsi and its validity and reliability have been approved in an independent study. The cut-off score of 23 has a high validity and reliability in Iran (19).

\subsection{Parenting Attitude Questionnaire}

This questionnaire has 30 items and three subscales; dominating, ignoring and possessive. It has been extracted from Shoben parenting attitude questionnaire by Drews and Teahan and has been translated to Farsi by
Broomandnasab, Shokrkonand and Najjarian (20). Each item is scored based on a five-grade scale, ranging from "I thoroughly agree" to "I thoroughly disagree". Higher score for each attitude indicates the type of parenting attitude for each person. Its validity is 55\% and its reliability is $66 \%$ for all the scales (20).

\subsection{Demographic Data Questionnaire}

It contains maternal age, job, education level, history of psychiatric disorders, number of children, children's age, sex, and order of birth.

\subsection{Statistical Analysis}

Descriptive statistical method, Pierson coefficient and Fisher's exact test, analysis of variance, T-test KruskalWallis, Man-Whitney, and logistic regression model were used. For data analysis, SPSS 16 was used ( $=0.05)$.

\begin{tabular}{|c|c|}
\hline \multicolumn{2}{|l|}{ Demographic Factors } \\
\hline \multicolumn{2}{|l|}{ Mothers } \\
\hline Age, y & $34.89 \pm 7.37$ \\
\hline \multicolumn{2}{|l|}{ Education level } \\
\hline Elementary & $10(16.7)$ \\
\hline High school & $33(55)$ \\
\hline Post-secondary school & $17(28.3)$ \\
\hline \multicolumn{2}{|l|}{ Occupation } \\
\hline Housewife & $19(41.3)$ \\
\hline Staff member & $14(30.4)$ \\
\hline employee & $2(4.3)$ \\
\hline Others & $11(23.9)$ \\
\hline \multicolumn{2}{|c|}{ History of psychiatric disorders } \\
\hline Yes & $4(7.1)$ \\
\hline No & $52(86.6)$ \\
\hline \multicolumn{2}{|l|}{ Children } \\
\hline Age, y & $7.51 \pm 2.74$ \\
\hline \multicolumn{2}{|l|}{ Gender } \\
\hline Male & $44(73.3)$ \\
\hline Female & $16(26.7)$ \\
\hline \multicolumn{2}{|l|}{ Order of birth } \\
\hline First & $33(55.9)$ \\
\hline Second & $17(28.8)$ \\
\hline Third & $6(10.2)$ \\
\hline Forth & $3(5.1)$ \\
\hline \multicolumn{2}{|l|}{ Number of children } \\
\hline 1 & $18(32.1)$ \\
\hline 2 & $26(46.6)$ \\
\hline 3 & $6(10.7)$ \\
\hline$\geq 4$ & $6(10.7)$ \\
\hline
\end{tabular}




\section{Results}

Table 1 shows the demographic data of mothers and their children. Table 2 shows the score of GHQ and parenting attitudes. Since the scores of GHQ and its subscales had asymmetric distribution, their modes are also reported in this table. Forty two (70\%) mothers were healthy and 18 (30\%) were unhealthy (Table 2). The scores of parenting attitude had a symmetric distribution; thus, their means were used (Table 2). Table 3 shows the relationship between the scores of GHQ and parenting attitude as well as some demographic factors. Pierson coefficient and Fisher's exact test showed a significant relationship in maternal age with both total score of GHQ $(\mathrm{r}=-0.350, \mathrm{P}=0.05)$ and the score of anxiety subscale $(\mathrm{r}$ $=-0.429, \mathrm{P}=0.05)$. There was no significant relationship between possessive attitude and the total score of GHQ. The GHQ total scores had asymmetric distribution, so that Kruskal-Wallis and Man-Whitney tests were used to assess the relationship between the GHQ scores and some demographic factors. This analysis did not show any relationship between these variables (Table 4). Table 5 shows the relationship between parenting attitude and some demographic factors of mothers and children. Mothers with elementary school education level had less possessive attitude than higher educated mothers $(P=0.017)$. Possessive and dominating attitude were not related to the mother's job, but ignoring attitude was significantly higher in staff members than others $(P=0.043)$ (Table 5). Logistic regression model also showed that the score of GHQ was significantly related to maternal age $(\mathrm{P}=0.027)$ and the number of children $(\mathrm{P}=0.011)$. Higher maternal age reduced the score of GHQ and increased the mothers' health level (Table 6).

\begin{tabular}{lcccc}
\hline \multicolumn{1}{l}{ Table 2. Means, Standard Deviations, and Quartiles of General Health Questionnaire and Parenting Attitude Scores ${ }^{\text {a }}$} \\
\hline Variables & Mean \pm SD & 1st Quartiles & 2nd Quartiles & 3rd Quartiles \\
\hline General health & & & & 27.75 \\
\hline Total GHQ & $21.83 \pm 12.17$ & 13 & 5.5 & 8 \\
\hline Anxiety & $6.15 \pm 5.01$ & 2 & 7.5 & 9 \\
\hline Social withdrawal & $7.45 \pm 2.53$ & 6 & 1 & 4 \\
\hline Depression & $2.93 \pm 4.13$ & 0 & 4.5 & 8 \\
\hline Somatic symptoms & $5.35 \pm 3.88$ & 3 & & 33 \\
\hline Parenting attitude & & & 30 & 32 \\
\hline Dominating & $29.45 \pm 5.71$ & 26 & 29 & 34 \\
\hline Possessive & $27.98 \pm 5.68$ & 24 & 29 & 3 \\
\hline Ignoring & $29.13 \pm 6.08$ & 24 & & 3 \\
\hline
\end{tabular}

a Abbreviation: GHQ, General Health Questionnaire.

\begin{tabular}{|c|c|c|c|c|c|}
\hline Variables & Total GHQ & Somatic Symptoms & Anxiety & Social Withdrawal & Depression \\
\hline \multicolumn{6}{|l|}{ Parenting attitude } \\
\hline Dominating & 0.122 & 0.127 & 0.181 & -0.001 & 0.031 \\
\hline Possessive & 0.174 & 0.137 & 0.215 & 0.164 & 0.025 \\
\hline Ignoring & 0.020 & 0.059 & 0.074 & 0.048 & -0.120 \\
\hline Age of mothers & $-0.350^{b}$ & -0.256 & $-0.429^{\mathrm{b}}$ & -0.024 & -0.236 \\
\hline Age of children & 0.062 & 0.142 & -0.016 & -0.057 & 0.109 \\
\hline Number of children & 0.095 & 0.156 & 0.028 & 0.129 & 0.037 \\
\hline Order of birth & 0.026 & 0.043 & -0.005 & 0.161 & -0.035 \\
\hline
\end{tabular}

\footnotetext{
a Abbreviation: GHQ, general health questionnaire.
}

$\mathrm{b}$ There is a significant relationship $(=0.05)$. 
Tashakori A et al.

\begin{tabular}{|c|c|c|c|c|c|}
\hline Variables & Total GHQ & Somatic Symptoms & Anxiety & Social Withdrawal & Depression \\
\hline \multicolumn{6}{|l|}{ Education level of mothers } \\
\hline Elementary & 17.5 & 6 & 4.5 & 6 & 2 \\
\hline High school & 18 & 4 & 5 & 8 & 1 \\
\hline Post-secondary school & 19 & 5 & 5 & 8 & 2 \\
\hline Pvalue & 0.604 & 0.708 & 0.846 & 0.180 & 0.380 \\
\hline \multicolumn{6}{|l|}{ Mothers' occupation } \\
\hline Housewife & 20 & 5 & 6 & 7 & 1 \\
\hline Employee/staff members & 16 & 4.5 & 5 & 8 & 1 \\
\hline Others & 18 & 5 & 4 & 8 & 1 \\
\hline P value & 0.120 & 0.201 & 0.369 & 0.239 & 0.263 \\
\hline \multicolumn{6}{|l|}{ Children's sex } \\
\hline Female & 18 & 6 & 4 & 8 & 1 \\
\hline Male & 18.5 & 4 & 5 & 7 & 1 \\
\hline P value & 0.688 & 0.642 & 0.701 & 0.365 & 0.605 \\
\hline
\end{tabular}

a Abbreviation: GHQ, General Health Questionnaire.

Table 5. The Relationship Between Parenting Attitude and Some Demographic Factors of Mothers and Children

\begin{tabular}{|lccc}
\hline Variables & Dominating & Possessive & Ignoring \\
\hline Education level of mothers & & & $26.70 \pm 7.27$ \\
\hline Elementary & $27.02 \pm 7.56$ & $23.40 \pm 2.22$ & $28.88 \pm 5.88$ \\
\hline High school & $29.27 \pm 5.51$ & $29.01 \pm 0.78$ & $31.06 \pm 5.40$ \\
\hline Post-secondary school & $31.23 \pm 4.52$ & $28.71 \pm 1.43$ & 0.187 \\
\hline P value & 0.172 & 0.017 & $27.84 \pm 7.12$ \\
\hline Mothers' occupation & & & $32.00 \pm 5.49$ \\
\hline Housewife & $29.05 \pm 6.654$ & $28.52 \pm 5.27$ & $26.90 \pm 4.61$ \\
\hline Employee/staff member & $31.62 \pm 4.81$ & $28.12 \pm 5.58$ & 0.043 \\
\hline Others & $28.18 \pm 4.33$ & $26.90 \pm 6.33$ & 0.748 \\
\hline P value & 0.236 & & $30.07 \pm 6.95$ \\
\hline Sex of children & & $26.93 \pm 6.27$ & $28.63 \pm 5.73$ \\
\hline Female & $31.06 \pm 4.81$ & $28.29 \pm 5.55$ & 0.433 \\
\hline Male & $28.81 \pm 5.96$ & 0.430 & \\
\hline Pvalue & 0.193 & & \\
\hline
\end{tabular}

Table 6. Results of Logistic Regression Model for Assessment of the Relationship Between General Health Questionnaire Scores and Parenting Attitude or Other Factors ${ }^{\mathrm{a}}$

\begin{tabular}{lllll}
\hline Variables & b & OR & SE & P Value \\
\hline Parenting attitude & & & & 0.600 \\
\hline Dominating & 0.07 & 0.13 & 1.07 & 0.839 \\
\hline Possessive & 0.03 & 0.13 & 1.03 & 0.651 \\
\hline Ignoring & -0.04 & 0.10 & 0.957 & 0.027 \\
Age of mothers & -0.30 & 0.138 & 0.737 & 0.336 \\
\hline Education level of mothers & & & 0.48 & 0.807 \\
\hline Elementary/ university & -0.73 & 0.76 & 0.81 & 0.011 \\
\hline High school/ university & -0.20 & 0.82 & 5.46 & 0.136 \\
\hline Number of children & 1.70 & 0.67 & 0.161 & \\
\hline Sex of children & -1.33 & 1.23 & & \\
\hline
\end{tabular}


Tashakori A et al.

\section{Discussion}

Our results showed that dominating, ignoring and possessive attitudes are frequent in mothers of ADHD children. This finding was consistent with the study of Hashemi and Hajjaran (21). Furthermore, Gau SS concluded that mothers of children with ADHD were more overprotective and controlling and less affectionate than mothers of control group (7). These parenting behaviors are seen in parents with possessive attitudes. Parents with dominating attitude have authoritarian parenting styles. Some studies relieved that authoritarian parenting style is prevalent in parents of children with ADHD and other behavioral disorder. A study by Lang et al. showed a higher level of authoritarian parenting style in parents of children with ADHD in comparison to other groups (9). In the study of Sadralsadat et al. authoritarian and uninvolved parenting styles were more frequent than authoritative parenting style in irresponsible families and families of children with behavioral disorder (22). Motamedi AA found that both fathers and mothers of students in Chahar Mahal-va-Bakhtiary province (Iran) were more authoritative with their daughters, while they were more authoritarian with their sons. In our study, parents with sons participated more than parents with daughters and they often used authoritarian parenting styles (23). Alizadeh studied the parenting styles in parents of adolescents with conduct disorder and concluded that these parents were less authoritative and more authoritarian than those of the control groups (15). Our study showed that ignoring parenting attitude in staff members was higher than others. These mothers may spend a lot of time out of home; so, their children receive caring from others. Therefore, these mothers do not have enough time to spend with their children and are not able to pay enough attention to childrearing. Other result of our study showed fewer possessive parenting attitudes in mothers with elementary school education level than mothers with higher education level. Mothers with higher education level may see more discrepancies between their potencies as well as the potency of their children. In other words, they may believe that their children must perceive help from their highly-educated mothers. In the current study, the results suggest that maternal general health is not related to parenting attitudes. It seems that parenting attitudes are affected by enduring and pervasive factors such as cultural context, meaths, and parenting in the family of origin. However, general health may change during short periods and perhaps cannot affect the parenting attitudes. Our study showed that each additional child increases the chance of being unhealthy for mothers. A possible explanation for this might be that mothers with more children, especially children with behavioral disorders, may experience more burdens, so they may be at risk of mental health problems. Another finding of our study was that higher maternal age increases the mothers' health. Presumably, older mothers are more adaptable with their children. Moreover, they are in different stages of personal and family life cycles, so that they may be more experienced and world oriented. Therefore, they may experience lower levels of anxiety symptoms. Our findings must be interpreted in the light of some limitations such as small sample size and limiting the study to clinical setting. In clinical setting, mothers of children with sever ADHD refer to psychiatric clinics more than mothers of children with mild ADHD. Severity of ADHD may affect the parenting attitudes. Both the relationship between possessive attitude and total score of GHQ and the relationship between possessive or dominating attitude and score of anxiety subscale may become significant by a larger sample size. In our study, children with ADHD were diagnosed through interview with a child and adolescent psychiatrist; thus, the questionnaires were filled under the supervision of the psychiatrist and the participants had access to a trained person for probable questions. Dominating, ignoring, and possessive attitudes are frequent in mothers of children with ADHD. Parenting attitudes in mothers of children with ADHD may have relationships with job and education level. Mothers of children with ADHD, especially with younger age and more offsprings, may be predisposed to mental health problems, particularly anxiety.

\section{Acknowledgements}

We thank the mothers who participated in this study.

\section{Funding/Support}

This manuscript was the product of the contract (Second parties are authors) No. u-90240 of Ahvaz Jundishpur University of Medical Sciences.

\section{References}

1. Spetie L, Arnold EL. Attention- deficit /hyperactivity disorder. In: Martin A, Volkmar FR editors. Lewis's child and adolescent psychiatry: a comprehensive textbook. 4th ed. Philadelphia: Lippincott Williams \& Wilkins; 2007. pp. 323-43.

2. Faraone SV, Sergeant J, Gillberg C, Biederman J. The worldwide prevalence of ADHD: is it an American condition? World Psychiatry. 2003;2(2):104-13.

3. Skounti M, Philalithis A, Galanakis E. Variations in prevalence of attention deficit hyperactivity disorder worldwide. Eur J Pediatr. 2007;166(2):117-23.

4. Shooshtary MH, Chimeh N, Najafi M, Mohamadi MR, Yousefi-Nouraie R, Rahimi-Mvaghar A. The prevalence of Attention Deficit Hyperactivity Disorder in Iran: A systematic review. Iran J Psychiatry. 2010;5(3):88-92.

5. Vasiri asfarjani SH, Tashakori A, Farhadibabadi S. [Prevalence of Attention Deficit Hyperactivity Disorder in Ahvaz city student and relation with some risk factors.21th international congress of pediatrics].Tehran: Tehran University of Medical Sciences; 2009.

6. Tashakori A, Afkandeh R. Prevalence of ADHD Symptoms amonge Male Preschoolers Based on Different Informants in Ahvas City of Iran. 2011;2011.

7. Gau SS. Parental and family factors for attention-deficit hyperactivity disorder in Taiwanese children. Aust $N$ Z J Psychiatry. 2007;41(8):688-96.

8. Modesto-Lowe V, Danforth JS, Brooks D. ADHD: does parenting style matter? Clin Pediatr (Phila). 2008;47(9):865-72. 
9. Lange G, Sheerin D, Carr A, Dooley B, Barton V, Marshall D, et al. Family factors associated with attention deficit hyperactivity disorder and emotional disorders in children. J Fam Ther 2005;27(1):76-96.

10. Chronis-Tuscano A, Raggi VL, Clarke TL, Rooney ME, Diaz Y, Pian J. Associations between maternal attention-deficit/hyperactivity disorder symptoms and parenting. J Abnorm Child Psychol. 2008;36(8):1237-50.

11. Young S. Coping strategies used by adults with ADHD. Pers Individ Dif. 2005;38(4):809-16.

12. Brook U, Boaz M. Attention deficit and hyperactivity disorder/ learning disabilities (ADHD/LD): parental characterization and perception. Patient Educ Couns. 2005;57(1):96-100.

13. Peters K, Jackson D. Mothers' experiences of parenting a child with attention deficit hyperactivity disorder. $J$ Adv Nurs. 2009;65(1):62-71

14. Oh WO, Kendall J. Patterns of parenting in Korean mothers of children with ADHD: A Q-methodology study. J Fam Nurs. 2009;15(3):318-42.

15. Alizadeh H, Applequist KF, Coolidge FL. Parental self-confidence, parenting styles, and corporal punishment in families of ADHD children in Iran. Child Abuse Negl. 2007;31(5):567-72.
16. Carr A. The handbook of child and adolescent clinical psychology: a contextual approach.New York: Routledge; 1999.

17. Conger JJ. Parent-Child Relationships, Social Change and Adolescent Vulnerability.J Pediatr Psychol. 1977;2(3):93-7.

18. Fathi Ashtiani A. Psychological tests, personality \& mental health.Tehran: Beasat; 1999.

19. Noorbala AA, Bagheriyazdi SA, Mohammad K. The Validation of General Health Questionnaire-28 as a Psychiatric Screening Tool. Hakim Res J. 2009;4:47-53.

20. Broomandnasab X. Assessment of relationship of parental attitudes and styles with locus of control and relationship of locus of control with educational function in 3ed grade middligngly students in Dezful city.Ahvaz: Shahid Chamran University; 1994.

21. Hashemi R, Hajjaran M. Assessment of relationship between parenting styles and their psychological maladaptive outcomes in Tehran.Zanjan; 2003.

22. Sadralsadat SJ, Shamsesfandabad H, Emamipour S. Parenting and family functioning among irresponsible families, families with behavioral disorder children and normalfamilies. Shahrekord Univ Med Sci J. 2005;7(2).

23. Motamedi AA. Parenting styles and their effect on children's education. J Psychol. 2009;12(1(48)):369-85. 